\title{
Somatostatin Impairs Sleep in Elderly Human Subjects
}

Ralf-Michael Frieboes, M.D., Harald Murck, M.D., Thomas Schier, M.D., Florian Holsboer, M.D., Ph.D., and Axel Steiger, M.D.

With increasing age, sleep becomes more shallow and fragmented and sleep-associated growth hormone (GH) release declines. GH secretion is regulated physiologically by opposite actions of GH-releasing hormone (GHRH) and somatostatin (SRIF). The administration of GHRH promotes sleep in both young and elderly controls, whereas SRIF does not induce sleep-EEG changes in young subjects. Because the influence of peripheral SRIF administration on sleep EEG in the elderly is unknown, we administered 50 $\mu g$ SRIF-14 every hour between 2200 and 0100 hours to controls with an age range from 60 to 73 years (mean $\pm S D$ $67.4 \pm 5.1$ years). After SRIF administration, total sleep time and rapid eye movement (REM) sleep decreased significantly, and more time was spent awake in the first sleep cycle, suggesting that SRIF induces sleep deterioration in the elderly. The peptide may become more effective on sleep EEG in older than in younger subjects, because of the decline of GHRH-GH axis activity, which may contribute to sleep disturbances in aging. The increased efficacy of SRIF in the elderly also may be explained by enhanced leakage of the blood-brain barrier. [Neuropsychopharmacology 16:339-345, 1997] (C) 1997 American College of Neuropsychopharmacology
KEY WORDS: Somatostatin; Sleep; Aging; REM sleep; GHRH; Sleep endocrinology

With increasing age, sleep continuity deteriorates, intermittent wakefulness increases physiologically, slow-wave sleep (SWS) declines and rapid eye movement (REM) latency is shortened. Some, but not all, studies have reported a decrease in the amount of REM sleep (Lauer et al. 1991; Bliwise 1993). Sleep tends to become shallow and fragmentated in the elderly. Women show better preservation of SWS, but in 80-year old probands there is a greater stability of sleep maintenance among men than women (Reynolds et al. 1991). Even changes in

From the Department of Psychiatry, Max Planck Institute of Psychiatry.

Address correspondence to: Ralf-Michael Frieboes, M.D., Max Planck Institute of Psychiatry, Department of Psychiatry, Clinical Institute, Kraepelinstrasse 10, D-80804 Munich, Germany.

Received May 13, 1996; revised September 26, 1996; accepted October 17, 1996. sleep-associated hormone secretion occur during aging. Growth hormone (GH) secretion is especially decreased in the elderly (Prinz et al. 1983; van Coevorden et al. 1991). This corresponding decline of SWS and GH secretion in aging and the rather strict association of SWS and the GH surge near the onset of sleep in man (Weitzman 1976; Steiger et al. 1987) suggest a common stimulating factor for the two phenomena. The secretion of $\mathrm{GH}$ is regulated physiologically in man and in the rat by GH-releasing hormone (GHRH), which enhances GH secretion from the pituitary, and somatostatin (SRIF), which opposes this effect (Brazeau et al. 1973; Müller 1987). SRIF is derived from a single gene that expresses a signal peptide that is cleaved into a propeptide. This molecule is processed into SRIF-28 and SRIF-14, which are the only ligands of SRIF receptors. SRIF-14- and SRIF-28-containing interneurons also are present in the hippocampal formation, amygdala, and hypothalamus, and most of them coexpress gamma-aminobutyric acid (GABA), which suggests a functional role of SRIF in inhibitory circuits (Epelbaum et al. 1994). 
In addition to their endocrine effects a role of GHRH and SRIF in sleep regulation also has been reported. Intracerebroventricular (ICV) (Ehlers et al. 1986; Obál et al. 1988) and intravenous (IV) (Obál et al. 1996) administration of GHRH increased SWS in rats. The promoting effect of GHRH on sleep also was demonstrated by the administration of a GHRH antagonist and GHRH antibodies, which caused decreases of non-REM and REM sleep in rats (Obál et al. 1991). In addition, SWS increases after IV administration of GHRH in young human controls (Steiger et al. 1991; Kerkhofs et al. 1993; Marshall et al. 1996). GHRH also promotes sleep in elderly human controls, as a significant decrease in the number of awakenings and an increase in the duration of the first non-REM period was found after pulsatile administration of GHRH to men and women older than 60 years, whereas SWS remained unchanged. The efficiency of GHRH is different in this age range (Guldner et al. 1994). During wakefulness, an age-dependent decline of the response of plasma GH concentration after GHRH administration has been reported in man (Shibasaki et al. 1984; Lang et al. 1987; Iovino et al. 1989). These findings are consistent with the view that GHRH is a stimulus common to both GH released from the pituitary and sleep generated in higher brain centers. In support of this view is a study that found decreased GH secretion and shallow sleep in patients with idiopathic dwarfism, in which central GHRH is lacking (Åström and Lindholm 1990).

The role of SRIF in sleep regulation is less clear. Rezek et al. (1977) administered various doses of SRIF into the amygdala of the rat. They found a dose-dependent decrease in the duration of REM sleep and "deep SWS," whereas "shallow SWS (drowsiness)" increased. Similarly Beranek et al. (1996) observed a suppression of non-REM sleep after systemic chronic administration of a long-acting SRIF analog to rats. In contrast, a series of studies by Danguir and coworkers suggested that SRIF promotes REM sleep in rats. These authors chronically infused SRIF ICV, which selectively enhanced the daily duration of REM sleep in young rats, whereas ICV administration of cysteamine, a selective SRIF depletor, resulted in a dose-dependent reduction of stage REM. Similarly, REM sleep was suppressed when central SRIF was neutralized by ICV infusion of SRIF antiserum (Danguir 1988). Intraperitoneal (IP) administration of an SRIF analog also produced a significant increase of REM sleep in adult rats (Danguir and De Saint-HilaireKafi 1988). Oral intake of the same SRIF analog also promoted REM sleep in aged rats (Danguir 1989). These data suggest a role for SRIF in the generation of REM sleep in the rat and led Danguir to hypothesize that sleep deficits during aging may be the result of decreased age-related SRIF release. This view is supported by two observations. First, the major effect of age on the sleep EEG in the rat is a decrease in REM sleep (Rosenberg et al. 1979). Second, some studies suggest age-related decreases of SRIF levels in the rat hypothalamus (Hoffman and Sladek 1980; Sirviö et al. 1987).

According to the wide distribution of SRIF terminals and its receptors (five of which are cloned) in the brain, numerous SRIF effects on neurotransmitter and neuropeptide release at various brain areas have been described. Consequently several behavioral effects have been discussed, but the exact role of SRIF on human sleep is not yet known.

In young controls during the third and the fourth decade of life, neither continuous (Parker et al. 1974; Kupfer et al. 1992) nor pulsatile administration of SRIF (Steiger et al. 1992) induced significant sleep EEG changes. The only effect of SRIF in young men was a trend of REM density (a measure of rapid eye movements during REM sleep) to increase (Steiger et al. 1992). We feel that GHRH and SRIF exert their reciprocal influence not only on GH release, but also on sleep. In young controls, GHRH counteracts the effects of SRIF on sleep EEG, whereas those effects occur in the elderly because of decreased GHRH activity. This prompted us to study the effects of SRIF on sleep in the elderly, in whom somatotrophic activity is low. Improved sleep after SRIF is suggested by Danguir's rat experiments already mentioned, but if SRIF has effects opposite to those of GHRH, sleep should deteriorate in a similar manner to the findings of Rezek and colleagues and of Beranek et al. To clarify this issue, we tested the effect of SRIF on sleep EEG in healthy elderly controls using a protocol in which the peptide SRIF-14 is administered every hour between 2200 and 0100 hours. This method of administration proved better than continuous administration (Guldner et al. 1994; Holsboer et al. 1988; Marshall et al. 1996; Steiger et al. 1991, 1992).

\section{METHODS}

\section{Subjects}

The study group consisted of seven paid healthy volunteers of normal weight and height (four males and three females, mean age: $67.4 \pm 5.1 \mathrm{SD}$; range $60-73$ years). Before entering the study, they underwent extensive physical, psychiatric, and laboratory examinations. Individuals with a personal or family history of psychiatric disorder or a recent stressful life event were excluded from the study. Laboratory tests included hematology, virology, clinical chemistry, endocrinology, EEG, and electrocardiography. Subjects who had made a transmeridian flight during the last 3 months were not admitted to the study. Sleep disorders such as sleep apnea, restless legs syndrome, or periodic movement syndrome were excluded by a 2-night screening registration in the 
sleep laboratory. Abuse of drugs, nicotine, alcohol, or caffeine and any history of medical treatment during the last 3 months also were reasons for exclusion. Written informed consent was received from all subjects before they entered the study. The study was approved by the Ethics Committee for Human Experiments of the Max Planck Institute of Psychiatry.

\section{Study Protocol}

The subjects had two sessions in the sleep laboratory at 1 -week intervals. SRIF or placebo was administered according to a randomized double-blind schedule. At each session the subjects spent two nights in the laboratory. The first night enabled adaptation to the laboratory setting. On the second day the subjects received an electrolyte- and calorie-balanced diet at 0800, 1200, and 1800 hours. An indwelling forearm catheter, which was kept patent with a $0.9 \%$ saline drip, was inserted at 1930 hours and connected to a plastic tubing extension that passed through a soundproof lock into the adjacent room. Polygraphic recordings (EEG, electrooculogram, electromyogram, and electrocardiogram) were monitored between 2300 and 0700 hours. The subjects were not allowed to sleep before "lights off" at 2300 hours, and they were awakened at 0700 hours. Outside of the period of polygraphic recording, naps were not allowed. During each session either $50 \mu \mathrm{g}$ SRIF-14 (Ferring, Kiel, Germany) or placebo was administered IV at four different times $(2200,2300,2400$, and 0100 hours). Sleep-EEG recordings were scored manually by a rater who was unaware of the treatment and experienced in the use of standard guidelines, as previously described (Rechtschaffen and Kales 1968; Holsboer et al. 1988).

\section{Statistics}

For all of the sleep variables investigated, group values were expressed as mean \pm standard deviation (SD). Mean differences between the placebo and SRIF groups were tested for significance with the paired Wilcoxon rank test. An alpha value of 0.05 was accepted as the nominal level of significance. Normally the differences had to be tested at a reduced level of significance to keep the type I error less or equal to the nominal level. But, the small sample size and the choice of the nonparametric Wilcoxon rank test make testing of null hypotheses against the alternative hypotheses very conservative. Supplementary reduction of the nominal level by applying for example the Bonferroni correction would make the testing extremely conservative and that would consequently lead almost surely to nonrejection of all null hypotheses, even in cases where the group means differ strongly from each other.

\section{RESULTS}

The sleep EEG variables after IV administration of SRIF and placebo are given in Table 1. Figure 1 illustrates how sleep EEG is changed by SRIF in one representative subject. At baseline conditions, sleep EEG variables were as expected in a sample of normal elderly controls (Williams et al. 1974; Lauer et al. 1991). The values of sleep latency, number of awakenings, and time spent awake were higher than commonly observed in normal young subjects. The REM latency was relatively short, whereas total sleep time, sleep efficiency index, amount of SWS, and particularly of stage 4 sleep, were low. After SRIF administration, total sleep time and REM sleep during the total night and the last third of the night decreased significantly. There was significantly more time spent awake in the first sleep cycle and during the first third of the night after SRIF. No further significant effects of the substance on sleep EEG variables, including the amount of SWS, was observed.

\section{DISCUSSION}

Our data show that repetitive peripheral administration of SRIF prompts sleep deterioration in elderly human subjects, which is consistent with the view that SRIF contributes to age-associated sleep EEG disturbances. At baseline, sleep architecture and sleep continuity of our sample of elderly controls were consistent with what is commonly observed (i.e., shallow and fragmentated sleep). After SRIF administration sleep EEG changes occurred that reflected further deterioration of sleep. In detail, total sleep time decreased after SRIF, mainly because of the significant decrease of REM sleep during the total night. REM sleep also decreased during the last third of the night at the time when the amount of stage REM is highest physiologically. Thus, application of SRIF during the first few hours of the night exerted a long-lasting suppressive effect on stage REM. On the other hand, intermittent wakefulness also increased significantly after SRIF, but this effect was restricted to the interval when the substance was injected. Therefore, the sleep efficiency index, which measures the relationship of percentages of wakefulness and sleep (without regard to stages) all over the night did not change significantly. We hypothesize that additional repeated applications of SRIF after 0100 hours until the early morning may result in a further decrease of the sleep efficiency.

Our present results are opposite to those seen after GHRH in young and old human control subjects and in animals. In young human subjects (Steiger et al. 1992; Kerkhofs et al. 1993; Marshall et al. 1996) and in animals (Ehlers et al. 1986; Obál et al. 1988) non-REM sleep, par- 
Table 1. Sleep EEG Variables after Placebo and SRIF Administration

\begin{tabular}{|c|c|c|c|}
\hline & $\begin{array}{c}\text { Placebo } \\
(\text { Mean } \pm \text { SD) }\end{array}$ & $\begin{array}{c}\text { SRIF } \\
(\text { Mean } \pm \text { SD) }\end{array}$ & $\begin{array}{c}\text { WRT } \\
1: 2\end{array}$ \\
\hline \multicolumn{4}{|l|}{ Sleep continuity } \\
\hline SPT (min) & $424.4 \pm 26.1$ & $405.7 \pm 54.8$ & NS \\
\hline TST (min) & $357.4 \pm 16.4$ & $339.8 \pm 40.5$ & $p \leqslant .05$ \\
\hline SEI & $0.84 \pm 0.5$ & $0.82 \pm 0.6$ & NS \\
\hline Sleep latency $(\mathrm{min})$ & $23.4 \pm 17.0$ & $28.0 \pm 25.3$ & NS \\
\hline Number of awakenings & $22.9 \pm 6.7$ & $27.0 \pm 8.6$ & NS \\
\hline \multicolumn{4}{|c|}{ Sleep architecture, minutes spent in each stage } \\
\hline \multicolumn{4}{|c|}{ During total night } \\
\hline Awake & $65.4 \pm 26.0$ & $68.7 \pm 31.4$ & NS \\
\hline Stage 1 & $40.6 \pm 15.2$ & $37.6 \pm 10.0$ & NS \\
\hline Stage 2 & $227.5 \pm 38.9$ & $230.9 \pm 54.3$ & NS \\
\hline Stage 3 & $15.0 \pm 15.6$ & $14.5 \pm 14.9$ & NS \\
\hline Stage 4 & $0.9 \pm 2.5$ & $0.4 \pm 0.8$ & NS \\
\hline SWS & $15.9 \pm 17.7$ & $15.0 \pm 15.3$ & NS \\
\hline REM & $68.0 \pm 13.1$ & $50.3 \pm 18.5$ & $p \leqslant .05$ \\
\hline Movement time & $2.9 \pm 0.8$ & $3.6 \pm 1.8$ & NS \\
\hline \multicolumn{4}{|l|}{ During first third of night } \\
\hline Awake & $6.5 \pm 3.0$ & $15.4 \pm 11.8$ & $p \leqslant .05$ \\
\hline \multicolumn{4}{|l|}{ During first sleep cycle } \\
\hline Awake & $0.9 \pm 1.1$ & $16.2 \pm 17.5$ & $p \leqslant .05$ \\
\hline Non REM & $44.9 \pm 18.0$ & $81.8 \pm 67.2$ & NS \\
\hline SWS & $4.4 \pm 5.8$ & $6.4 \pm 11.0$ & NS \\
\hline REM & $20.5 \pm 9.6$ & $13.8 \pm 5.3$ & NS \\
\hline \multicolumn{4}{|l|}{ REM variables } \\
\hline REM latency (min) & $44.9 \pm 18.0$ & $81.8 \pm 67.2$ & NS \\
\hline REM density & $2.2 \pm 0.6$ & $2.6 \pm 1.1$ & NS \\
\hline REM last third of night ( $\mathrm{min}$ ) & $20.9 \pm 6.2$ & $8.7 \pm 5.2$ & $p \leqslant .05$ \\
\hline
\end{tabular}

Abbreviations: SPT, sleep period time; TST, total sleep time; SEI, sleep efficiency index; SWS, slow-wave sleep (stages 3 and 4); REM, rapid eye movement sleep; WRT, Wilcoxon rank test; NS, not significant. All results are given as mean $\pm \mathrm{SD}$.

ticularly SWS, increased after GHRH. A similar, though weaker effect was found in elderly men and women (Guldner et al. 1994). In some (Obál et al. 1988; Kerkhofs et al. 1993; Marshall et al. 1996), but not all (Steiger et al. 1992), studies REM sleep also was enhanced after GHRH. GHRH in young men (Steiger et al. 1992) and SRIF in the elderly had a similar long-lasting duration of action. After the two peptides either an increase of SWS (GHRH) or a decrease of REM sleep (SRIF) was detectable until the last third of the night. This observation demonstrates that peptides are capable of inducing sleep EEG changes for at least 6 hours, although their half-life time is much shorter. Our results are consistent with those by Rezek et al. (1977), who found impaired sleep after SRIF in the rat, specifically decreased REM sleep and SWS and increased shallow sleep. Similarly Beranek et al. (1996) reported a decrease of Non-REM sleep after a SRIF analog. These studies differ from the reports by Danguir and coworkers, which showed an increase of stage REM in young and in old rats after ICV and systemic administration of SRIF and its analog and a decrease of stage REM after pharmacological in- hibition of SRIF (Danguir 1986, 1988, 1989; Danguir and De Saint-Hilaire-Kafi 1988, 1989). These data suggest that SRIF promotes REM sleep selectively, whereas our study and that of Rezek and coworkers show a decrease of REM sleep after SRIF. This variance may derive from methodological issues because we examined the effect of the peptide on one night's sleep and Rezek et al. monitored a 2-hour interval. Danguir and coworkers, however, recorded sleep in the rat for up to 7 consecutive days and compared the amount of REM sleep after administration for the whole day with either saline or the substance.

Finally our data show that effects of SRIF on sleep EEG are age-dependent. Previous reports in young subjects failed to find sleep EEG effects of SRIF (Parker et al. 1974; Kupfer et al. 1992; Steiger et al. 1992). GHRH and the SRIF systems may be affected differently by age, and this could be the reason why SRIF is ineffective in young subjects but modulates sleep in elderly subjects. An age-related decrease in the hypothalamic content of GHRH (Morimoto et al. 1988) and mRNA levels (De Gennaro Colonna et al. 1994) has been described in 


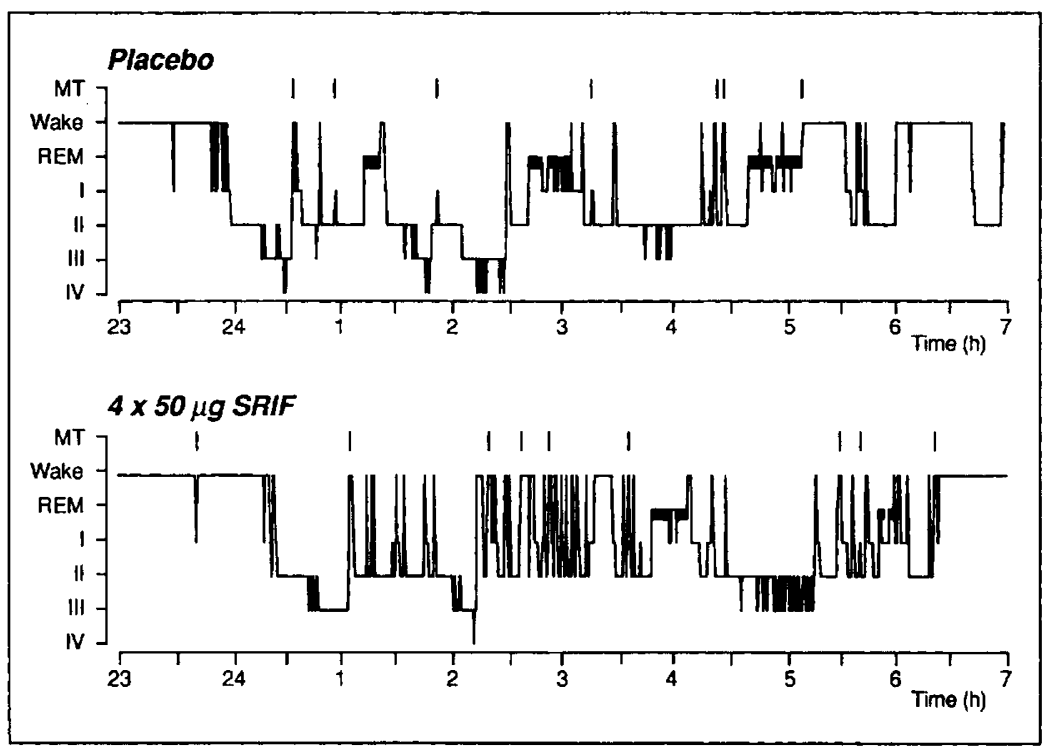

Figure 1. Sleep pattern in one subject after placebo and SRIF. MT, movement time; REM, rapid eye movement sleep; I-IV, Non-REM sleep stages 1 to 4 . the rat. Some reports also have described diminished SRIF levels (Hoffman and Sladek 1980; Sirviö et al. 1987) and a reduced hypothalamic SRIF gene expression (Sonntag et al. 1990) in the brain of old rats. Clinical studies in man, however, failed to show decrements in SRIF levels in the cortex and cerebrospinal fluid (CSF) with increasing age (Ferrier and Leake 1990). Furthermore, the fractional efflux of SRIF from hypothalamic neurons of median eminence slices in old rats is higher than in young rats in vitro (Sonntag et al. 1986). An increased pituitary response to SRIF-14 was reported in aging rats. Briefly, the GHRH-induced release of GH was lower in old than in young or middle-aged rats in the presence of SRIF (Spik and Sonntag 1989). On the other hand, no significant change of hypothalamic SRIF mRNA was found between old rats and young rats (De Gennaro Colonna et al. 1994). In summary, our data and the literature suggest that GHRH-GH axis activity and efficacy are reduced and SRIF secretion remains primarily unchanged in the elderly. This would explain why endogenous GHRH counteracts the sleep disturbing effects of endogenous and exogenous SRIF in younger subjects. In the elderly, the decreased GHRH secretion activity and the increased SRIF:GHRH ratio may possibly contribute to shallow sleep.

Our study also corroborates that specific CNS effects of neuropeptides are induced when they are injected IV in a pulsatile fashion. For example, corticotropin-releasing hormone (Holsboer et al. 1988), GHRH (Steiger et al. 1992), ACTH (4-9) (Steiger et al. 1991), growth hormone-releasing peptide (Frieboes et al. 1995), and vasoactive intestinal polypeptide (Murck et al. 1996) exert specific effects on the sleep EEG in normal men. In addition, Obál et al. (1996) demonstrated recently that both IV and ICV GHRH administration prompts similar influences on sleep EEG in the rat. As discussed in detail elsewhere (Steiger et al. 1991; Steiger 1995), it is unlikely that the sleep EEG changes after these peptides are secondary to their challenge of peripheral hormone secretion. The main endocrine effect of SRIF is suppression of $\mathrm{GH}$, which results in increased central release of GHRH via feedback control. By this route an increase of SWS would be expected, which is opposite to what we found. SRIF neurons with cell bodies in the ventricular hypothalamic nucleus and its terminals in the external zone of the median eminence on the fenestrated vessels of the portal system are perhaps the prime target by which externally administered SRIF may enter the brain and then diffuse to various brain sites. It even seems possible that SRIF may become more effective on sleep EEG with increasing age because of an age-dependent increase in blood-brain barrier leakage. However, in elderly controls GHRH administered peripherally is less effective on sleep EEG than in younger subjects (Steiger et al. 1992; Guldner et al. 1994). Our findings do not support this hypothesis.

Previous research has suggested that learning and memory functions are related to the amount of REM sleep and central SRIF activity. A set of human and animal studies supports the view that enhanced learning results in increased REM sleep and that REM sleep plays a central role in memory and learning (Crick and Mitchison 1995). On the other hand, pharmacological depletion of SRIF levels caused cognitive impairment in rats (Haroutunian et al. 1987), whereas environmental stimulation improved performance in a spatial learning situation and resulted in activation of cortical and hypothalamic SRIF levels (Nilsson et al. 1993). It often is found that SRIF is reduced in CSF of patients with Alzheimer's disease (Bissette and Myers 1992). Destruc- 
tion of SRIF-containing interneurons of the temporal cortex and hippocampus has been described in this disorder (Chan-Palay 1987). The functional relevance of decreased SRIF production was demonstrated by a decreased SRIF brain level that correlated with cognitive impairment (Francis et al. 1987). Interestingly, there is an association between low SRIF levels in CSF and decreased REM sleep in Alzheimer's disease, although this REM sleep inhibition also may be caused by decreased acetylcholine levels (Bliwise 1993). Our present data, however, suggest that normal or elevated SRIF levels decrease REM sleep in normal elderly humans. Therefore, the relationship between SRIF activity, REM sleep, and cognition in the elderly needs further clarification.

To our knowledge there are no reports on disturbed sleep after therapeutic use of SRIF or SRIF analogs in patients with acromegalia or gastroenteropancreatic tumors. However, it is likely that these side effects remain unrecognized because, when left untreated, these diseases may affect sleep. Thus, the patient's ability to sleep may subjectively benefit from successful treatment. It is important to recognize that long-term treatment of gastroenteropancreatic tumors may induce insomnia in elderly patients.

\section{ACKNOWLEDGMENTS}

This study was supported by a grant from the Deutsche Forschungsgemeinschaft (Ste 486/1-2).

\section{REFERENCES}

Åström C, Lindholm J (1990): Growth hormone-deficient young adults have decreased deep sleep. Neuroendocrinology 51:82-84

Beranek L, Obál Jr F, Bodosi B, Taishi P, Laczi F, Krueger JM (1996): Inhibition of Non-REM sleep in response to a long-acting somatostatin analogue, somatostatin, in the rat. J Sleep Res 5 (suppl 1):14

Bissette G, Myers B (1992): Somatostatin in Alzheimer's disease and depression. Life Sci 51:1389-1410

Bliwise DL (1993): Sleep in normal aging and dementia. Sleep 16:40-81

Brazeau P, Vale W, Burgus R, Ling N, Butcher M, Rivier J, Guillemin R (1973): Hypothalamic polypeptide that inhibits the secretion of immunoreactive pituitary growth hormone. Science 179:77-79

Chan-Palay V (1987): Somatostatin immunoreactive neurons in the human hippocampus and cortex shown by immunogold/silver intensification of vibratome sections: Coexistence with neuropeptide $Y$ neurons, and effects in Alzheimer-type dementia. J Comp Neurol 260:201-223

Crick F, Mitchison G (1995): REM sleep and neural nets. Behav Brain Res 69:147-155
Danguir J (1986): Intracerebroventricular infusion of somatostatin selectively increases paradoxical sleep in rats. Brain Res 367:26-30

Danguir J (1988): Internal milieu and sleep homeostasis. In Inoué S, Schneider-Helmert D (eds), Sleep Peptides: Basic and Clinical Approaches. Tokyo, Japan Scientific Societies Press, pp 53-72

Danguir J (1989): The somatostatin analogue SMS 201-995 promotes paradoxical sleep in aged rats. Neurobiol Aging $10: 367-369$

Danguir J, De Saint-Hilaire-Kafi S (1988): Scopolamineinduced suppression of paradoxical sleep is reversed by the somatostatin analogue SMS 201-995 in rats. Pharmacol Biochem Behav 30:295-297

Danguir J, De Saint-Hilaire-Kafi S (1989): Reversal of desipramine-induced suppression of paradoxical sleep by a long-acting somatostatin analogue (octreotide) in rats. Neurosci Lett 98:154-158

De Gennaro Colonna V, Cella SG, Parenti M, Locatelli V, Cocchi D, Müller EE (1994): Neuroendocrine aging: Its impact on somatotrophic function. Neurochem Int 25:5-10

Ehlers CL, Reed TK, Henriksen SJ (1986): Effects of corticotropin-releasing factor and growth hormone-releasing factor on sleep and activity in rats. Neuroendocrinology 42:467-474

Epelbaum J, Dournaud P, Fodor M, Viollet C (1994): The neurobiology of somatostatin. CRC Crit Rev Neurobiol $8: 25-44$

Ferrier IN, Leake A (1990): Peptides in the neocortex in Alzheimer's disease and aging. Psychoneuroendocrinology 15:89-95

Francis PT, Bowen DM, Lowe SL, Neary D, Mann DM, Snowden IS (1987): Somatostatin content and release measured in cerebral biopsies from demented patients. J Neurol Sci 78:1-16

Frieboes RM, Murck H, Maier P, Schier T, Holsboer F, Steiger A (1995): Growth hormone-releasing peptide-6 stimulates sleep, growth hormone, ACTH and cortisol release in normal man. Neuroendocrinology 61:584-589

Guldner J, Frieß E, Colla-Müller M, Schier T, Holsboer F, Steiger A (1994): Influence of GHRH on sleep EEG and on nocturnal secretion of cortisol, $\mathrm{ACTH}$ and $\mathrm{GH}$ in elderly normal controls. Exp Clin Endocrinol 102 (suppl 1):69

Haroutunian V, Mantin R, Campell GA, Tsuboyama GK, Davis KL (1987): Cystamine-induced depletion of central somatostatin-like immunoreactivity: Effects on behavior, learning, memory and brain neurochemistry. Brain Res 403:234-242

Hoffman GE, Sladek JR (1980): Age-related changes in dopamine, LHRH and somatostatin in the rat hypothalamus. Neurobiol Aging 1:27-37

Holsboer F, von Bardeleben U, Steiger A (1988): Effects of intravenous corticotropin-releasing hormone upon sleeprelated growth hormone surge and sleep EEG in man. Neuroendocrinology 48:32-38

Iovino M, Monteleone R, Steardo L (1989): Repetitive growth hormone-releasing hormone administration restores the attenuated growth hormone $(\mathrm{GH})$ response to $\mathrm{GH}$ releasing hormone testing in normal aging. J Clin Endocrinol Metab 69:910-913 
Kerkhofs M, van Cauter E, van Onderberghen A, Caufriez A, Thorner MO, Copinschi G (1993): Sleep-promoting effects of growth hormone-releasing hormone in normal men. Am J Physiol 264:E594-598

Kupfer DJ, Jarrett DB, Ehlers CL (1992): The effect of SRIF on the EEG sleep of normal men. Psychoneuroendocrinology 17:37-43

Lang I, Schernthaner G, Pietschmann P, Kurz R, Stephenson JM, Templ H (1987): Effects of sex and age on growth hormone response to growth hormone-releasing hormone in healthy individuals. J Clin Endocrinol Metab 65:535-540

Lauer CJ, Riemann D, Wiegand M, Berger M (1991): From early to late adulthood. Changes in EEG sleep of depressed patients and healthy volunteers. Biol Psychiatr 29:979-993

Marshall L, Mölle M, Böschen G, Steiger A, Fehm HL, Born J (1996): Greater efficacy of episodic than continuous growth hormone (GHRH) administration in promoting slow-wave sleep (SWS). J Clin Endocrinol Metab 81: 1009-1013

Morimoto N, Kawakami F, Makino S, Chihara K, Hasegawa M, Ibata Y (1988): Age-related changes in growth hormone releasing factor and somatostatin in the rat hypothalamus. Neuroendocrinology 47:459-464

Müller EE (1987): Neural control of somatotrophic function. Physiol Rev 67:962-1053

Murck H, Guldner J, Colla-Müller M, Frieboes RM, Schier T, Wiedemann K, Holsboer F, Steiger A (1996): Vasoactive intestinal polypeptide decelerates nonREM-REM cycles and modulates hormone secretion during sleep in men. Am J Physiol 271:R905-R911

Nilsson L, Mohammed A, Henriksson B, Folkesson R, Winblad B, Bergström L (1993): Environmental influence on somatostatin levels and gene expression in the rat brain. Brain Res 628:93-98

Obál Jr F, Alföldi P, Cady AB, Johannsen L, Sary G, Krueger JM (1988): Growth hormone-releasing factor enhances sleep in rats and rabbits. Am J Physiol 255:R310-R316

Obál Jr F, Payne L, Kapás L, Opp M, Krueger JM (1991): Inhibition of growth hormone-releasing factor suppresses both sleep and growth hormone secretion in the rat. Brain Res 557:149-153

Obál Jr F, Floyd R, Kapás L, Bodos B, Krueger JM (1996): Effects of systemic GHRH on sleep in intact and in hypophysectomized rats. Am J Physiol 263:E230-237

Parker DC, Rossman LG, Siler TM (1974): Inhibition of the sleep-related peak in physiologic human growth hormone release by somatostatin. J Clin Endocrinol Metab 38:496-499

Prinz PN, Weitzman ED, Cunningham GR, Karacan I (1983): Plasma GH during sleep in young and aged men. J Gerontol 38:519-524

Rechtschaffen A, Kales A (1968): A Manual of Standardized Terminology Techniques and Scoring System for Sleep
Stages of Human Subjects. Bethesda, MD, U.S. Department of Health, Education and Welfare, Neurological Information Network

Reynolds CF, Monk TH, Hoch CC, Jennings JR, Buysse DJ, Houck PR, Jarrett DB, Kupfer DJ (1991): Electroencephalographic sleep in the healthy "old old": A comparison with the "young old" in visually scored and automated measures. J Gerontol Med Sci 46:M39-M46

Rezek M, Havlicek V, Hughes KR, Friesen H (1977): Behavioural and motor excitation and inhibition induced by the administration of small and large doses of somatostatin into the amygdala. Neuropharmacology 16: 157-162

Rosenberg RS, Zepelin H, Rechtschaffen A (1979): Sleep in young and old rats. J Gerontol 34:525-532

Shibasaki T, Shizume K, Nakahara M (1984): Age related changes in plasma growth hormone response to growth hormone-releasing factor in man. J Clin Endocrinol Metab 58:212-214

Sirviö J, Julkonnen J, Pitkänen A, Riekinen PJ (1987): Age dependence of somatostatin levels and somatostatin binding in the rat brain. Comp Biochem Physiol 87A: 355-357

Sonntag WE, Gottschall PE, Meites J (1986): Increased secretion of somatostatin-28 from hypothalamic neurons of aged rats in vitro. Brain Res 380:229-234

Sonntag WE, Boyd RL, Booze RM (1990): Somatostatinergic gene expression in hypothalamus and cortex of aging male rats. Neurobiol Aging 11:409-416

Spik K, Sonntag WE (1989): Increased pituitary response to somatostatin in aging male rats: Relationship to somatostatin receptor number and affinity. Neuroendocrinology 50:489-494

Steiger A (1995): Schlafendokrinologie. Nervenarzt 66:15-27

Steiger A, Herth T, Holsboer F (1987): Sleep-electroencephalography and the secretion of cortisol and growth hormone in normal controls. Acta Endocrinol 116:36-42

Steiger A, Guldner J, Knisatschek H, Rothe B, Lauer C, Holsboer F (1991): Effects of an ACTH/MSH(4-9) analog (HOE 427) on the sleep EEG and nocturnal hormonal secretion in humans. Peptides 12:1007-1010

Steiger A, Guldner J, Hemmeter U, Rothe B, Wiedemann K, Holsboer F (1992): Effects of growth hormone-releasing hormone and somatostatin on sleep EEG and nocturnal hormone secretion in male controls. Neuroendocrinology 56:566-573

van Coevorden A, Mockel J, Laurent E, Kerkhofs M, L'Hermite-Balériaux $M$, Decoster $C$, Nève $P$, van Cauter $E$ (1991): Neuroendocrine rhythms and sleep in aging men. Am J Physiol 260:E651-661

Weitzman ED (1976): Circadian rhythms and episodic hormone secretion in man. Ann Rev Med 27:225-243

Williams RL, Karacan I, Hursch CJ (1974): Electroencephalography (EEG) of Human Sleep: Clinical Applications. New York, Wiley 